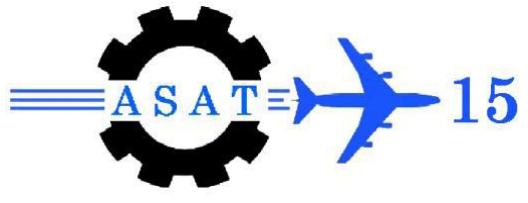

\title{
Hybrid Valve with Variable Performance Curves
}

\author{
H. A. Heikal*, E. B. Shafik ${ }^{\dagger}$, R. M. Abd El-Maksoud ${ }^{*}$
}

\begin{abstract}
Pipeline valves have been studied extensively to determine their inherent performance characteristics. However, some researchers introduced different internal designs for such valves to achieve the required characteristic. Consequently, this paper presents a new valve concept that consists of two identical portions of global type valves arranged in series configuration. The interaction between the two valve portions achieves an inherent flow coefficient range instead one performance curve. Experimental investigation is herein performed while studying the opening of the two valve portions, the variation of upstream pressure, Reynolds number and pressure loss coefficient. The investigation puts some global guidelines for valve performance and cavitation avoidance.
\end{abstract}

Keywords: Valve, inherent performance characteristics, flow coefficient, pressure loss coefficient.

\section{Introduction}

Many researches [1-4] have been adopted to study the flow control valves due to their importance in controlling various engineering applications. Studies were concerned to determinate the inherent performance characteristics of the valve [5-6]. However, few researches introduced different internal design of the valve to achieve a variety of inherent performance characteristics, [5, 7-10]. The present research aim is to introduce a new valve having an infinite number of inherent characteristic curves and satisfying different system demands. The present valve is composed of two portions arranged in series configuration. The valve characteristic of each valve portion and the interaction between the two portions are studied while considering different parameters.

\section{The Present Valve and the Test Rig}

Figure 1 demonstrate the primary concept of the new valve that is divided into two valve portions (seats) in series arrangement. The two valve portions have identical dimensions. Each of the valve portions can be used separately to control the flow rate when the other is partially or fully opened. The interaction between the two valves introduces a characteristic range instead of the valve inherent characteristic curve. The present valve can permit the flow

Professor, Dept. of Mech. Power Eng., Helwan University, Cairo, Egypt.

$\dagger$ Demonstrator, Dept. of Mech. Power Eng., Helwan University, Cairo, Egypt, engemeel@gmail.com

$\$$ Assistant professor, Dept. of Mech. Power Eng., Helwan University, Cairo, Egypt, brainandspirit@yahoo.com 
through it in both directions. The angles of the right and left plugs are the same and equal to $74^{\circ}$ measured from the axial direction. The area of each of the valve portions is equal to half of the internal cross section area of the pipe attached to the valve.

Figure 2 depicts the assembly drawing of the present valve. The valve is manufactured from AISI 304 stainless steel material and valve is machined internally using a CNC milling machine. The overall dimensions of the new valve are $155 \mathrm{~mm}$ length and $145 \mathrm{~mm}$ diameter. Each of the valve portion internal diameters is equal to that of the pipe $(520 \mathrm{~mm})$. Two valve keys that are manually actuated are used to control the opening of the left and right valve portions. The internal diameter of the valve portions is equal to that if the pipe.

A schematic diagram of the test rig is presented in Fig. 3. The setup is designed according to the standard test method of ANSI/ISA-75.02-1996. The test rig consists of a main water tank, centrifugal pumps, piping system, flow meter, the new designed control valve and some accessories. A reservoir has $2 \mathrm{~m} \times 2 \mathrm{~m} \times 1.5 \mathrm{~m}$ and a pump of type Calpeda (NM40/16 AE) were used to properly supply the water with the maximum flow rate and pressure required in a testing line. The present valve is placed between two pressure transducers with resolution 0.01 mbar and with the pressure range of 0 bar to 10 bars and accuracy $\pm 0.2 \%$ of full scale. The upstream and downstream pressures are measured at a distance of two and six pipe diameters, respectively according to ANSI/ISA-75.01.01-2002. The static tabs, which are used for static pressure measurements, are machined and welded in the pipelines upstream and downstream the present valve. The diameter and height of the static tap holes are 5 and 25 $\mathrm{mm}$, respectively. The diameter of the static tap holes has been chosen to be $10 \%$ of the pipe diameter and its height five times its diameter, according to ASME performance test code PTC 19.5-1972. The pressure drop across the present valve is accomplished by adjusting the upstream and downstream ball valves.

A magnetic flow meter is used to measure the flow rate of the water flowing through the tested valve. The flow-speed range of the transducer was $0.02 \mathrm{~m} / \mathrm{s}-8 \mathrm{~m} / \mathrm{s}$ with accuracy $\pm 1 \%$ of full scale. The experimental measurements of flow rate through the present valve and pressure upstream and downstream the new valve as well are recorded by using an A/D converter (data acquisition) PCI card, NI 6220 (by National Instruments), 8 differential channel, 16 bits ADC resolution with a maximum sampling rate of $250 \mathrm{kHz}$. The connection to the card is done using different input. The differential input connection is used to reduce noise signal, and it is installed on a desktop computer with $933 \mathrm{MHz}, 512 \mathrm{MB}$ RAM. The measurements are monitored and recorded using LabVIEW V8.1. software. The program is designed to receive the measured signal as a voltage analog signal. These voltage signals are converted to pressure in $\mathrm{kPa}$, displayed and recorded versus time with a sample frequency of $50 \mathrm{kHz}$ and stored on the hard disk of the PC. During the experimental work, the maximum temperature change of water temperature does not exceed $5^{\circ} \mathrm{C}$ during one hour. The water temperature is measured using handheld digital thermometer (EXTECH, 445715) which has a resolution of $0.1^{\circ} \mathrm{C}$ and accuracy of $\pm 1^{\circ} \mathrm{C}$ within -10 to $50^{\circ} \mathrm{C}$. The flow coefficient is assigned by the following equation, Leephakpreeda [5]:

$\ln Q=\ln \mathrm{C}_{v}+0.5 \ln \Delta \mathrm{p}$

where $\mathrm{Q}$ is the flow rate in $\mathrm{m}^{3} / \mathrm{s}, \Delta \mathrm{p}$ is different between upstream pressure and downstream pressure across the valve in $\mathrm{kP}, \mathrm{C}_{\mathrm{v}}$ is the flow coefficient. Leephakpreeda [5] assigned flow coefficient, $\mathrm{C}_{\mathrm{v}}$, when the pressure drop reaches unity makings its logarithmic value zero. Hence, the logarithmic value of $\mathrm{C}_{\mathrm{v}}$ is equal to the logarithmic value of the flow rate. In addition, the value of the slope is equal hypothetically to 0.5 , and the value of the interception 
at vertical axis is equal to the logarithmic value of $\mathrm{C}_{\mathrm{v}}$. In order to determine the full valve opening, the measurement procedure is undertaken till the variations of $\mathrm{C}_{\mathrm{v}}$ is diminutive.

\section{Results and Discussion}

Figure 4 shows the logarithmic relation between the variation of the pressure drop across the left valve portion and the variation in the flow rate passing through it at fixed openings for the left valve portion. It can be seen that the slopes in all cases are nearly constant and close to the theoretical value of 0.5, Eq.1. According to [5], the intersection of the lines with the y axis of the plot assigns the flow coefficient. Therefore, for certain, each group of points that is represented by line is used to assign one value of $\mathrm{C}_{\mathrm{v}}$. The values of flow coefficients for different left valve portion determines the valve characteristic. Moreover, the right valve portion gives typically the same characteristic as left one under same flow conditions and direction.

Figures 5 and 6 demonstrate the relation between the valve flow coefficient and the valve opening for three different upstream pressures. The upstream flow is passing in the direction of the left of the valve as shown in these figures as well to all the following figures. As one can notice that the change in upstream pressure has insignificant effect in inherent characteristic of the valve as it is confirmed by [6]. Regarding the two figures together, the inherent characteristic of each valve portion is different due to the direction of the flow relative to the valve position and its geometric arrangement.

Figures 7 and 8 illustrate the relation between the valve flow coefficient and the valve opening for two values of the Reynolds number of the flow passing upstream the valve. These figures indicate that the change in Reynolds number has insignificant effect on the inherent characteristic of the present valve as it is confirmed by [6]. Consequently, the flow velocity upstream the valve has a minor influence on the valve performance.

Figures 9 and 10 shows the effect of valve opening on the pressure loss coefficient (ratio of the pressure drop across the valve to the kinetic energy of the flow upstream the valve) for the two value portions. There is a significant effect of small valve openings on the pressure loss coefficient. However, beyond this range; an inconsequential effect is observed. Moreover, the upstream pressure variation has a minor effect on the pressure loss coefficient. Comparing the results of the two figures with each other, it is clear that the right valve portion has more impact on such coefficient with large closures. This makes a precaution of using it in small upstream pressures and high temperature flows in order to avoid cavitation.

Figures 11 and 12 display the contribution of the two portions on the valve flow coefficient. The left valve plug operates from valve closure to full open position, and the right valve plug is opened at fixed values of $25 \%, 50 \%, 75 \%$, and $100 \%$ of its full opening at upstream pressure $100 \mathrm{kP}$. The interaction between the two valve portions achieves an infinite number of inherent characteristic curves instead of one unique valve characteristic. Additionally, $\mathrm{C}_{\mathrm{v}}$ changes drastically with the operation of the two portions together. It is shown that the change of right valve portion and the left have fixed values valve, Fig.12, achieves a large operating range than the other curve, Fig.11. This is due to the flow direction effect. It is noted that the upstream pressure and Reynolds number have insensible effects when the two valve portions work together. However, the results concerned such two parameters have not demonstrated in figures as they are confirmed by the previous results in Figs. 5 to 8. 
Figures 13 and 14 exemplify the effect of interaction between the two valve portions on the pressure loss coefficient. This interaction achieves the pressure loss coefficient variation in an operating range instead of single characteristic line (Figs. 9 and 10). This privilege is important when changing the interaction between the two valve portions to achieve a lower pressure loss coefficient. This reduces the possibility of valve cavitation when the value is subjected to server flow conditions. It is clear that change right valve opening while the left valve portion is fixed to a specific opening achieves a higher pressure loss coefficient. Consequently, it is recommended that the valve portion ahead the upstream flow should not subjected to large closures especially for the flow having small upstream pressures and/or high temperatures in order to avoid cavitation.

\section{Conclusions}

From this work, the following conclusions may be drawn:

1. The present paper introduced a new valve that is composed of two valve portions arranged in series configuration.

2. The two valve portions have typically the same characteristic under same flow conditions and direction. However, their inherent characteristics differ from each other when the direction of the flow relative to the valve position and its geometric arrangement is different.

3. The upstream pressure and Reynolds number have an insignificant effect on the valve flow coefficient.

4. The interaction between the valve portions changes the flow coefficient and gives band of the inherent characteristic instead of a unique characteristic associated with each of the valve portion.

5. Operating the two valve portions together reduces spectacularly the pressure losses through the valve and consequently avoids as possible the valve cavitation.

6. In order to avoid cavitation, it is recommended that the valve portion ahead the upstream flow should not subjected to large closures especially for the flow having small upstream pressures and/or high temperatures.

\section{References}

[1] Eom, K., "Performance of butterfly valves as a flow controller", Journal of fluids engineering, vol. 110, pp 16-19, (1988).

[2] Campagne, C.V., "Nicodemus, R., Bruin, G.J., and D., Lohse., "A method for pressure calculation in ball valves containing bubbles", J. of fluids engineering, vol. 124, pp 765771, (2002).

[3] Davis, J.A., and M., Stewart., "Predicting globe control valve performance - Part I: CFD Modeling", J. of fluids engineering, vol. 124, pp 772-777, (2002).

[4] Jazi, A.M., and H. Rahimzadeh., "Waveform analysis of cavitation in a globe valve" Ultrasonics, vol. 49, pp 577-582, (2009).

[5] Leephakpreeda, T., "Design factors for "linear" ball valve: theoretical and experimental studies", Songklanakarin Journal of Science. Technol., vol. 27, pp 353-361, (2005).

[6] Chern, M.J., and Wang, C.C., and C.H. Ma., "Performance test and flow visualization of ball valve", Experimental thermal and fluid science, vol. 31, pp 505-512, (2007).

[7] Oki, I., and Kawakami, K., "Characteristics of flat-seated valves with broader seatface”, The japan society of mechanical engineers 4(14), pp 2278-286, (1961).

[8] Oki, I., "Influence of effective head on the characteristics of flat-seated valve", The japan society of mechanical engineers 6(23), pp 467-478, (1963). 
[9] Johnston, D.N., Edge, K.A., and N.D. Vaughan., "Experimental investigation of flow and force characteristics of hydraulic poppet and disc valves", J. of power and energy, vol. 205, pp 161-171, (1991).

[10] Chern, M.J., and C.C. Wang., "Control of volumetric flow-rate of ball valve using Vport”, J. of fluids engineering, vol. 126, pp 471-481, (2004).

[11] Nawar, M.A., "New valve with variable inherent performance for different system characteristics", Ph.D, Mechanical power Dpt., Faculty of Eng., Mataria, Helwan university, (2010).

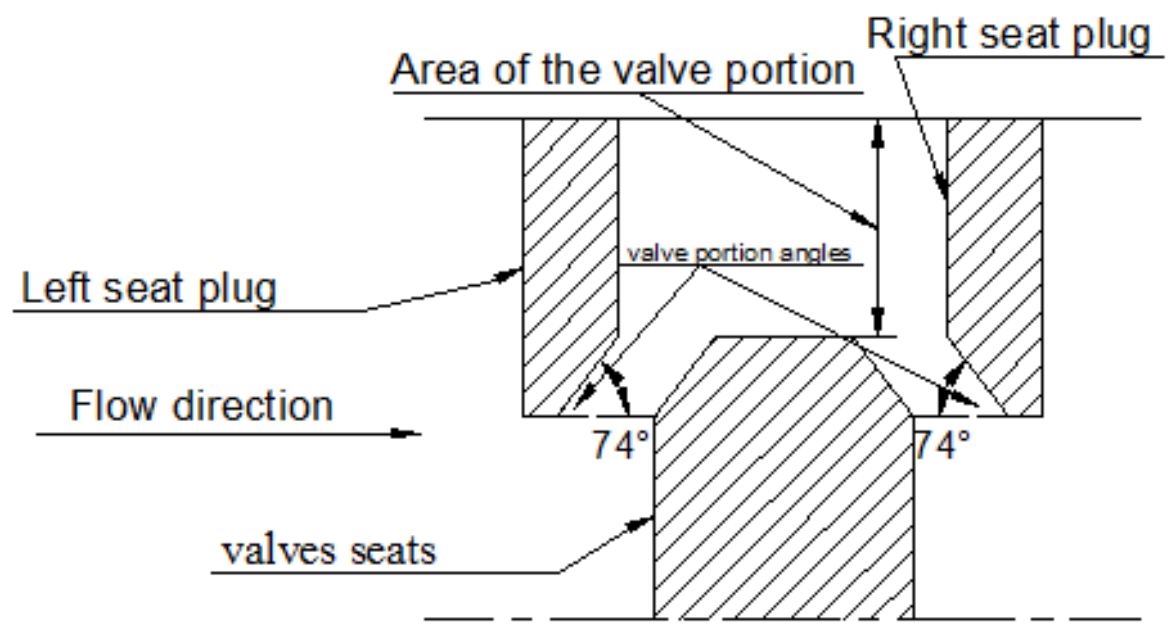

Fig.1. Schematic diagram of the new valve.

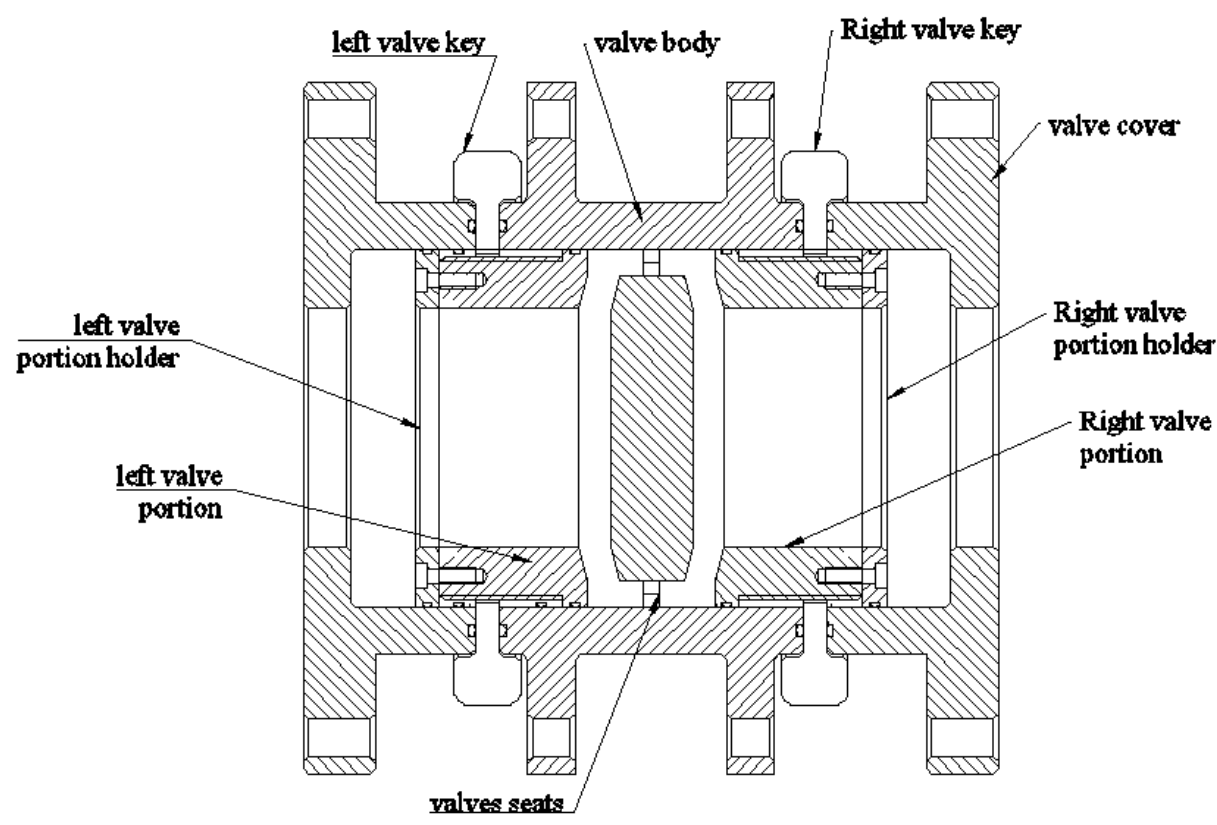

Fig.2. Assembly drawing of the new valve. 


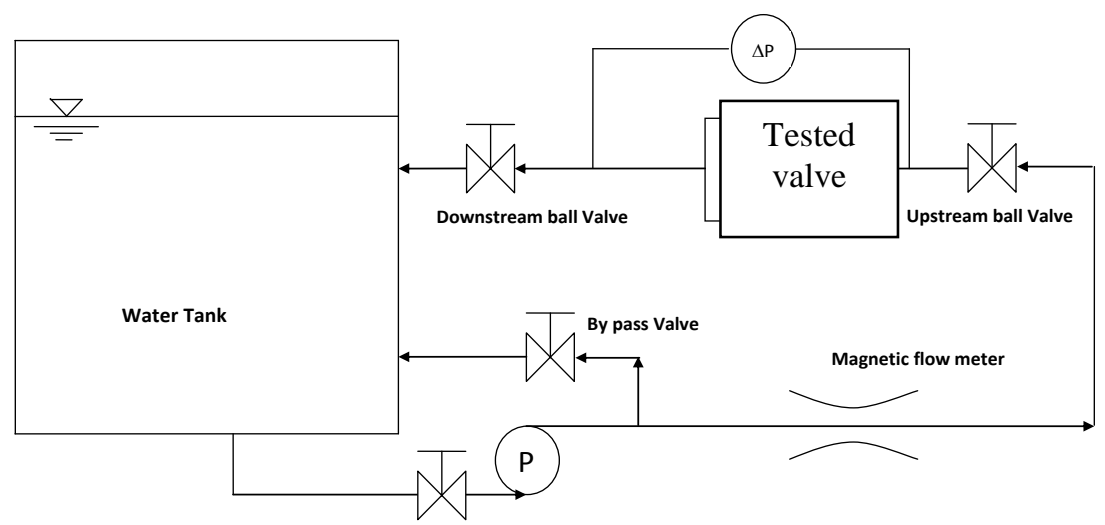

Fig.3. Schematic diagram of the test rig.

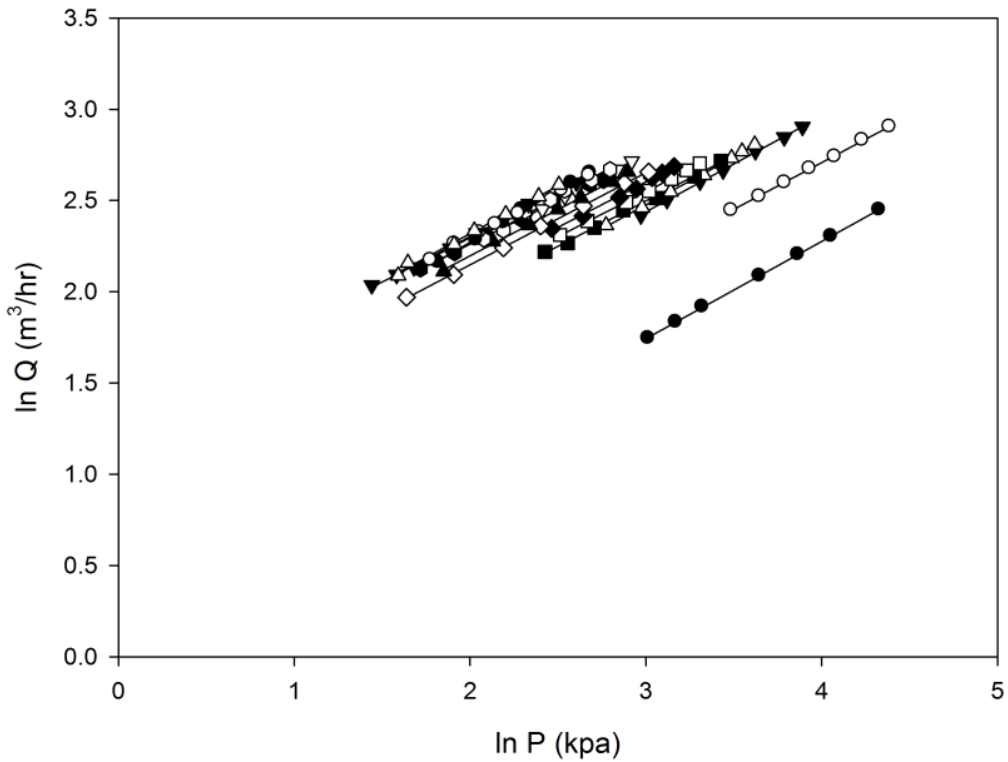

valve trave

Fig.4. Relation between flow rate and pressure drop of the left valve portion. 


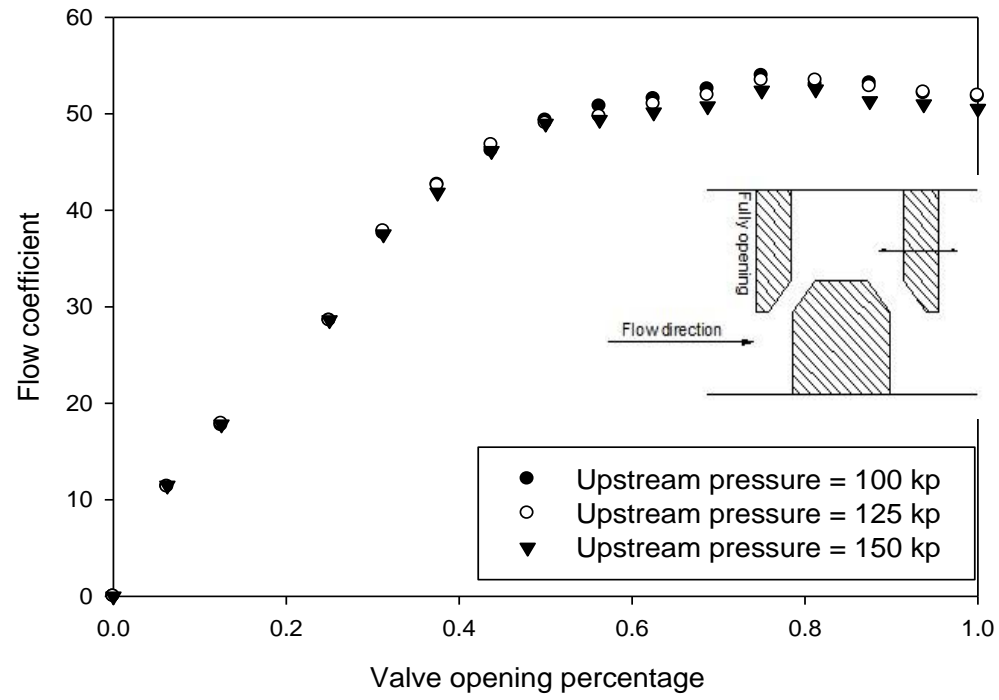

Fig.5. Flow coefficient of the right valve portion with change in upstream pressure.

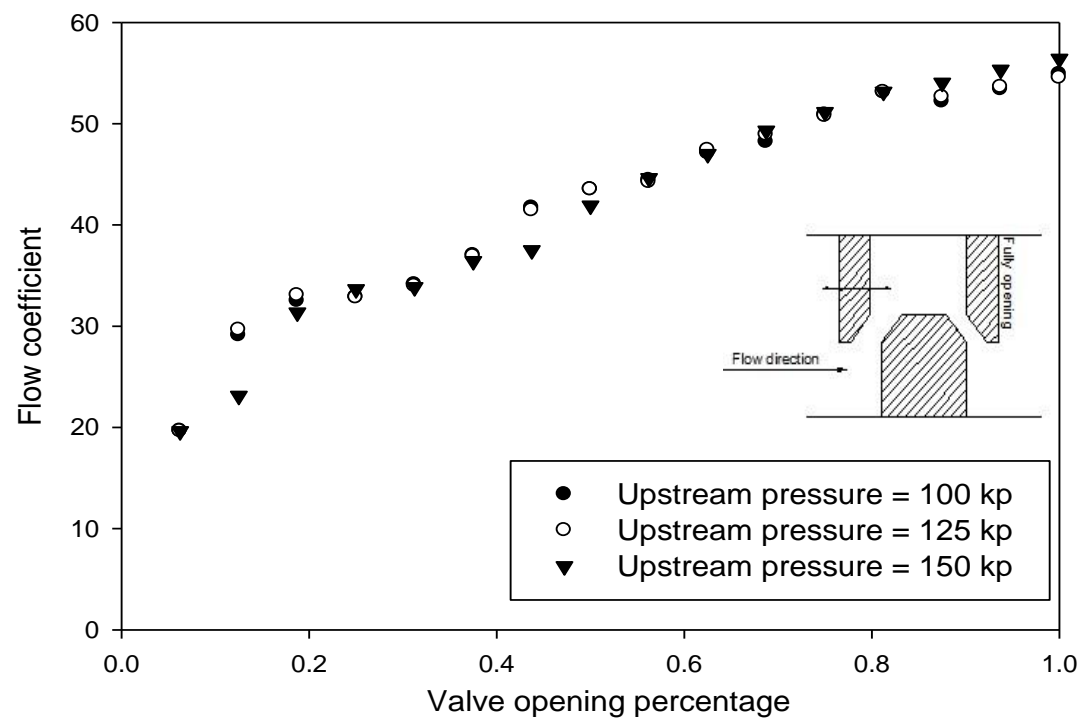

Fig.6. Flow coefficient of the left valve portion with change in upstream pressure. 


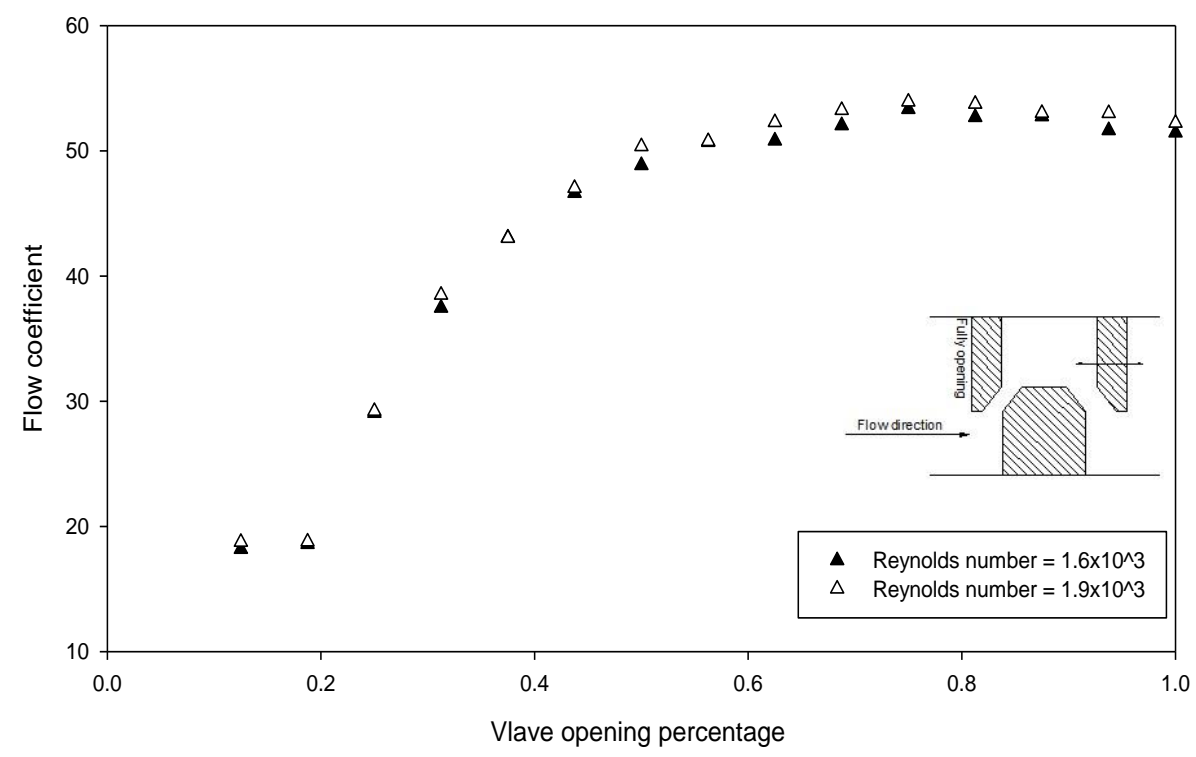

Fig.7. Flow coefficient of the right valve portion with change Reynolds number.

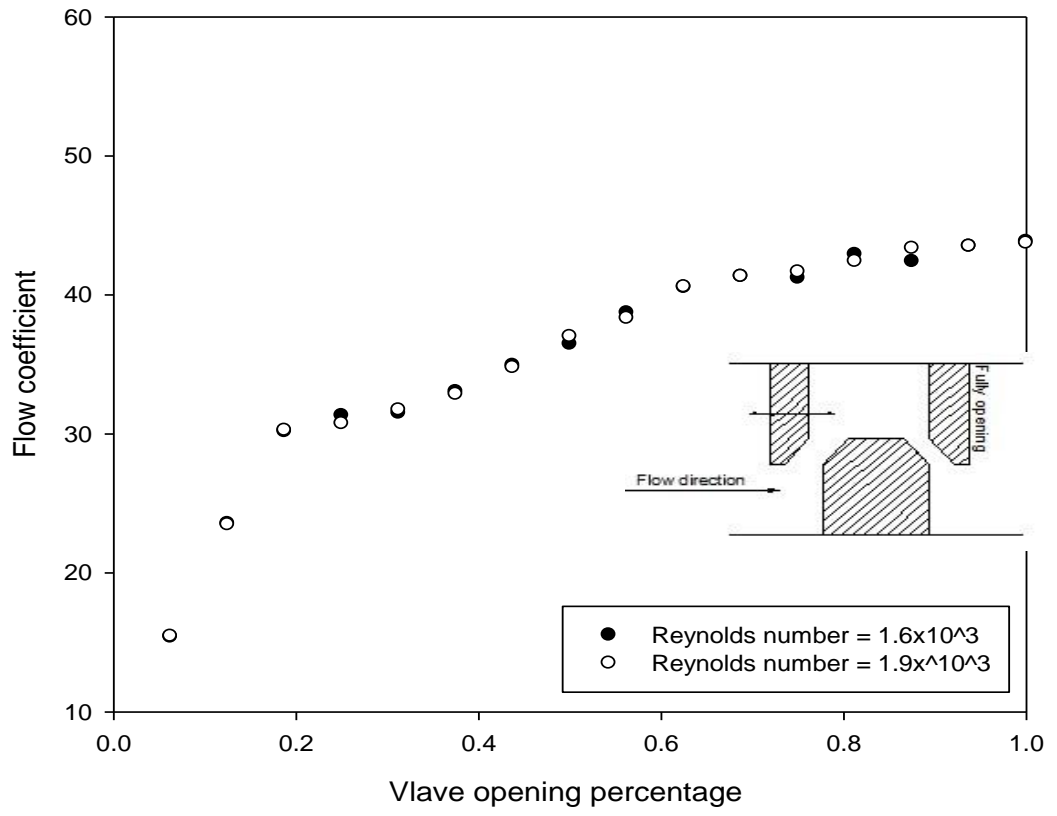

Fig.8. Flow coefficient of the left valve with change Reynolds number. 


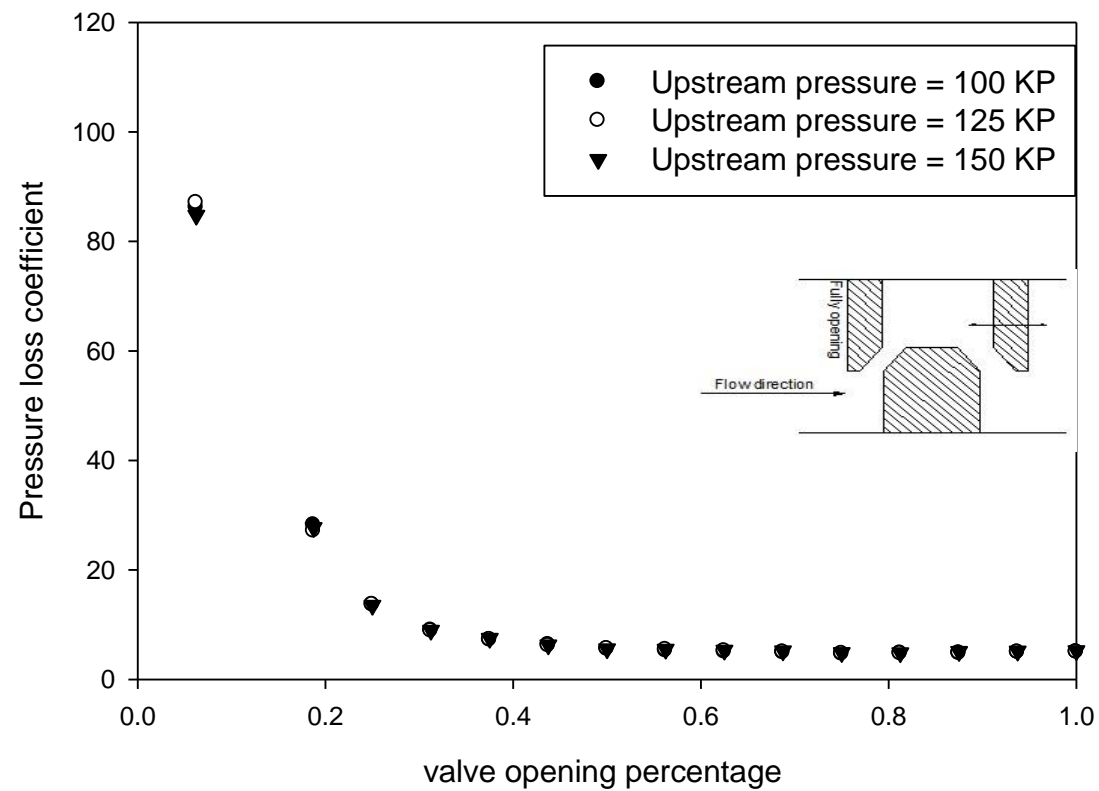

Fig.9. Pressure loss coefficient of the right valve portion with change upstream pressure.

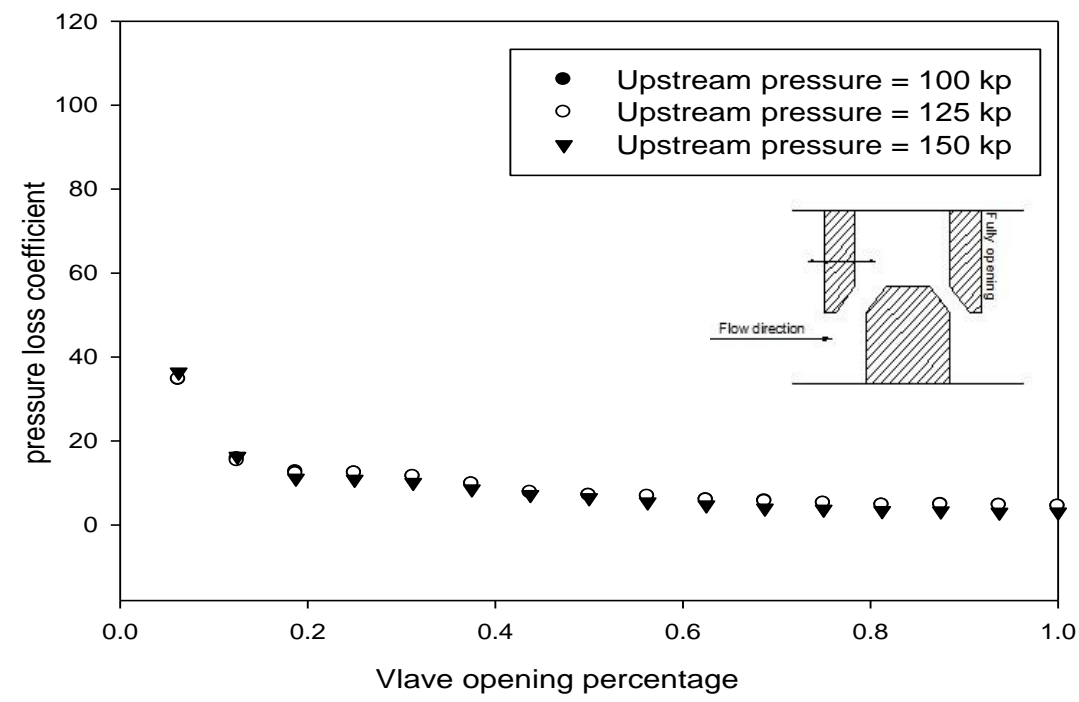

Fig.10. Pressure loss coefficient of the left valve portion with change upstream pressure. 


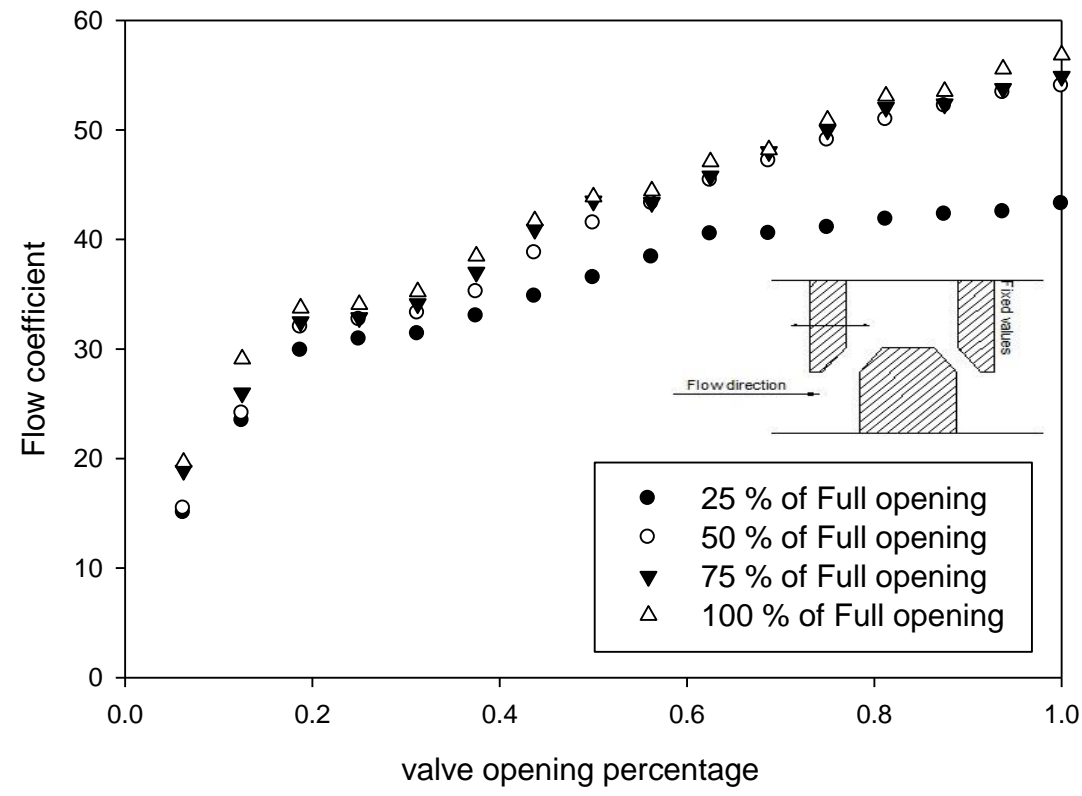

Fig.11. Flow coefficient of the left valve for different specific right valve opening.

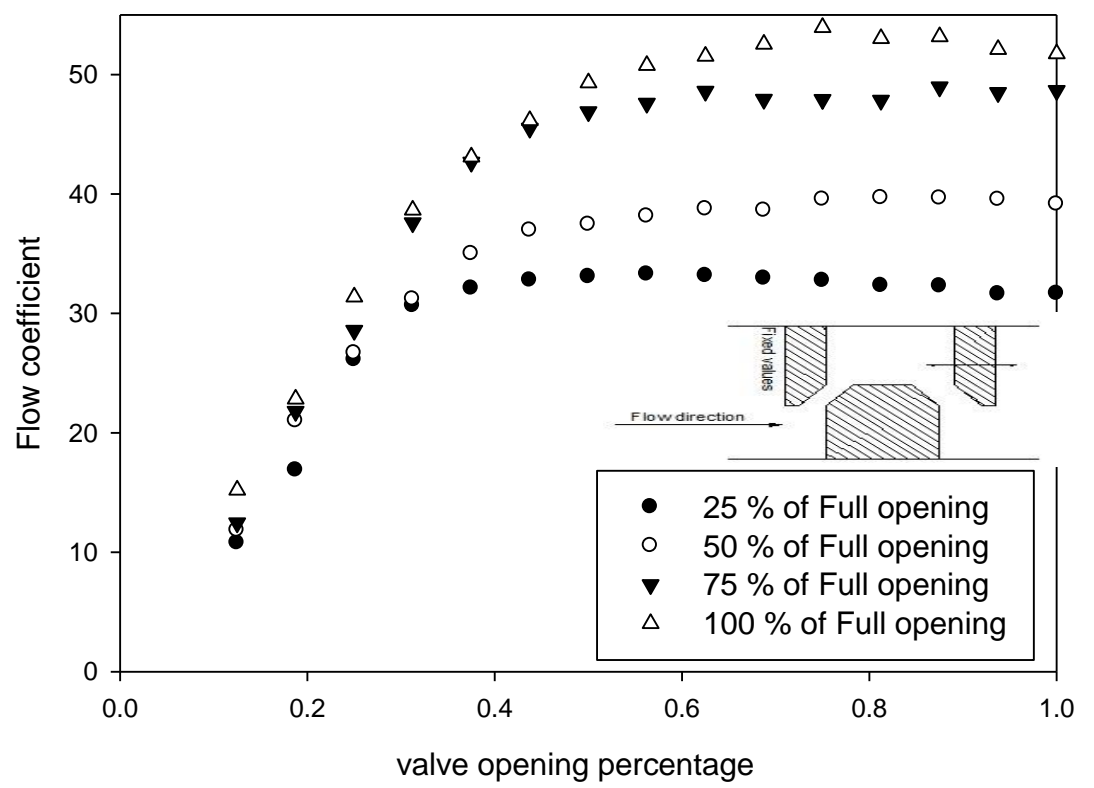

Fig.12. Flow coefficient of the right valve portion for different specific left valve opening. 


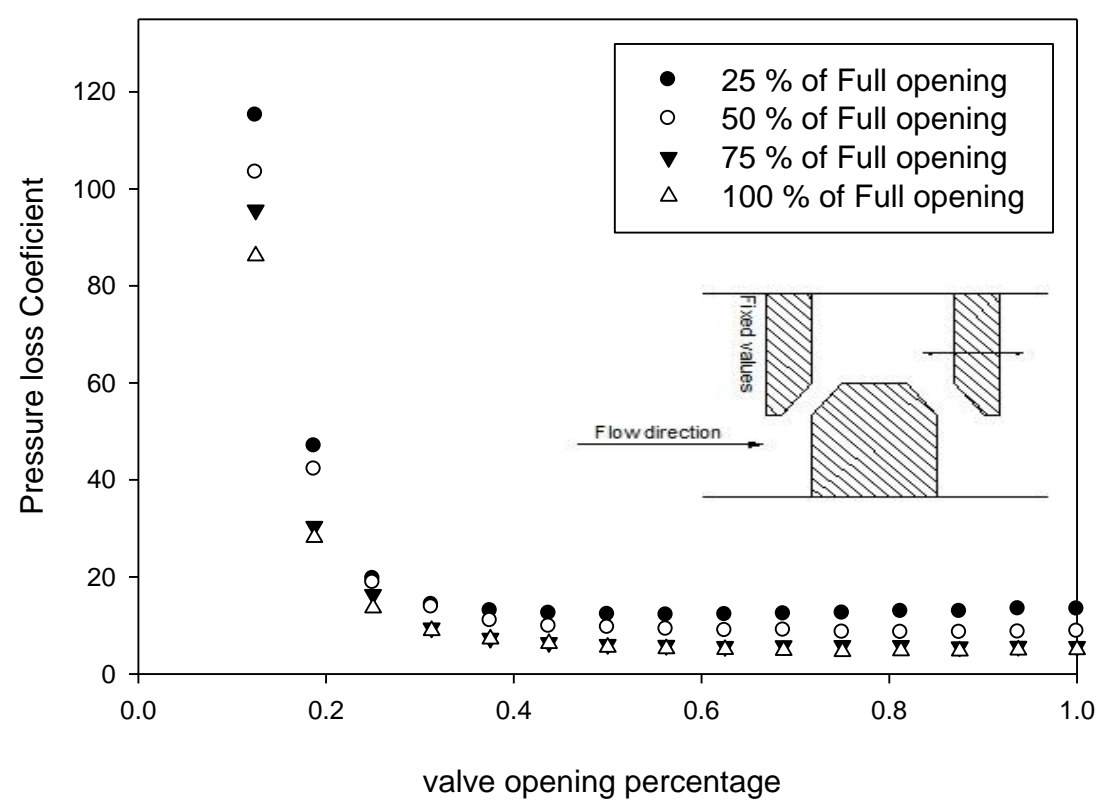

Fig.13. Pressure loss coefficient of the right valve for different specific left valve opening.

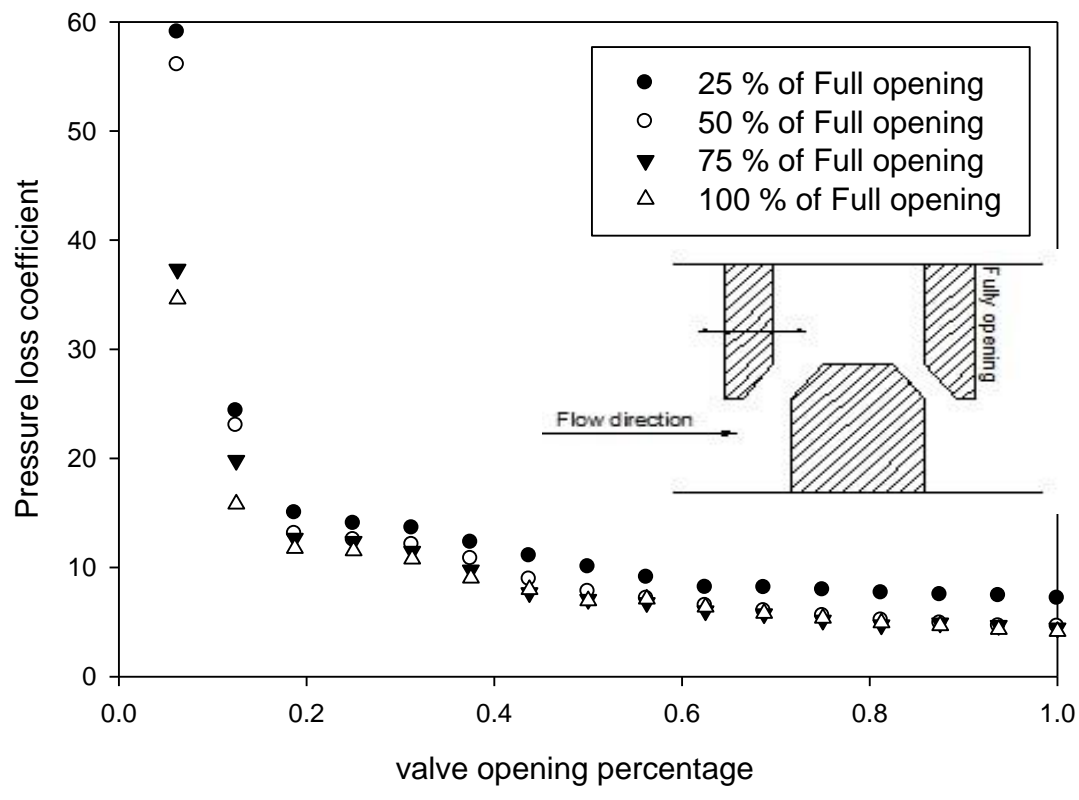

Fig.14. Pressure loss coefficient of the left valve for different specific right valve opening. 